\title{
Editorial
}

\section{Explorers and Settlers}

Our language has many names for someone who crosses from familiar to unfamiliar geographical terrain: adventurer, pioneer, immigrant, colonist, trailblazer, among others. Each word labels a different complex activity.

The history of science, too, is full of instances of scientists whose careers and interests have led them to work in areas outside those in which they were trained and who did so in many different ways. The articles in this issue describe several varieties of boundary-crossing - and in one case, boundary-creation-that we might call exploring and settling.

Leyla Joaquim, Olival Freire Jr., and Charbel El-Hani discuss several physicists whom they call explorers of the biological realm. The science of living beings, charted by biologists and naturalists for centuries, was no terra incognita. Yet it was new ground for physicists who, as these authors relate, attempted to use the conceptual tools and experimental methods of quantum physics in a wholly new domain to address animate matter. The visionary Niels Bohr tried to extend his idea of complementarity to biology, inspiring Pascual Jordan to pursue those initiatives further. Their concepts were more speculative than concrete, remaining grounded in physics, expressing imaginative visions rather than grappling with biological realities. Bohr and Jordan passed rather briefly through biological terrain, only venturing general ideas and impressions; they might better be called tourists than explorers. But, the authors continue, the physicist Max Delbrück moved wholesale into biology, "uncovering its riddles and mastering its language and culture."

To pioneer bacteriophage research in the laboratory, Delbrück had to master and extend the painstaking experimental techniques of microbial studies so as to encompass the new work of bacteriophages and viruses. He went native, becoming a settler, one who follows the pioneers and starts long-lasting projects that eventually become self-sustaining. In contrast to pioneers, settlers do not act alone or just make wild surmises; they colonize the new country, establishing larger bodies of workers that build a new society. Delbrück, along with the growing number who joined in the projects of the phage group, established molecular biology in ways that went far beyond the speculations of Bohr.

Next, Simón Reif-Acherman examines the dynamics of exploring and settling from another angle, detailing how the British physicist Hugh Longbourne Callendar used his study of thermodynamics to carry thermometry into a new realm of precision. We aptly speak of "settling a question," implicitly drawing on the 
vocabulary of settlers, who stabilize and complete the work of the pioneers. ReifAcherman reveals the new ways Callendar settled issues of temperature. Having pioneered new thermometric materials, such as platinum, Callendar then confronted the significantly different kind of activities needed to establish their decisive findings. To settle the ascendancy of the platinum thermometer, Callendar had to bring it to a new degree of experimental purity as well as give theoretical arguments for its superiority.

Another kind of settling is involved in Adam Fix's account of the French mathematician and physicist Joseph Sauveur. Fix describes how this hearing-impaired pioneer of acoustics went on to try to settle its status as "a science superior to music." Sauveur placed mechanical and mathematical principles on one side of the border; left on the other side were the subjective, unquantifiable, and unmeasurable phenomena themselves. According to Fix, not only did Sauveur thereby infuse the content and methods of acoustics with new rigor but also decisively repositioned it vis-à-vis the artistic realm of music theory. In the process, Sauveur severed what had been an ancient connection between the two, establishing acoustics as an autonomous science.

We find such tales of pursuit across traditional research boundaries to have a certain beauty and dignity. Even more than intelligence or insight, they often involve risk and heroism, whose role in physics deserves continuing attention.

Robert P. Crease Peter Pesic 